\title{
Atividades motoras e qualidade de vida de adolescentes de Paranaguá, Paraná
}

\author{
Motor practices and quality of life of adolescents of Paranagua, Parana
}

\section{AUTORES \\ Geraldo Jose Ferrari Junior ${ }^{1}$ (DD \\ Raísa Carvalho da Silva ${ }^{1}$ (D) \\ Bruna Adamar Castelhano Soares ${ }^{1}$ (D) \\ Thais Silva Beltrame ${ }^{1}$ (ID \\ Andreia Pelegrini ${ }^{1}$ (I) \\ Érico Pereira Gomes Felden ${ }^{1}$ (D) \\ 1 Universidade do Estado de Santa Catarina - UDESC; Centro de Ciências da Saúde e Esporte - CEFID, Florianópolis, Santa Catarina, Brasil.}

\section{CONTATO}

Geraldo Jose Ferrari Junior geraldo_ferrari@hotmail.com Rua Pascoal Simone, 358, Coqueiros, Florianópolis, Santa Catarina, Brasil. CEP: 88080-350.

DOI

$10.12820 /$ rbafs.23e0018

\section{(2) $\Theta \Theta$}

Copyright: This is an open-access article distributed under the terms of the Creative Commons Attribution License ${ }^{\circledR}$, which permits unrestricted use, distribution, and reproduction in any medium, provided that the original author and source are credited.

\begin{abstract}
RESUMO
O objetivo do estudo foi analisar as relações entre o envolvimento em diferentes atividades motoras, de acordo com a frequência de prática, e a percepção da qualidade de vida de adolescentes. Participaram do estudo 773 adolescentes das escolas estaduais de Paranaguá (Paraná), com idade de 14 a 19 anos. Por meio de um questionário autoaplicável, foram coletadas informações sociodemográficas, a atividade motora (Physical Activity Questionnaire for Adolescents) e percepção da qualidade de vida (Pediatric Quality of Life Inventory ${ }^{T M}$, versão 4.0). Adolescentes que praticavam futebol $(\mathrm{p}<0,005)$, basquete $(\mathrm{p}<0,005)$, lutas $(\mathrm{p}<0,005)$, musculação $(\mathrm{p}<0,001)$, tênis/tênis de mesa $(\mathrm{p}<0,005)$, natação $(\mathrm{p}<0,0005)$, voleibol $(\mathrm{p}<0,005)$, ginástica na academia $(\mathrm{p}<0,005)$ e andavam de bicicleta $(\mathrm{p}<0,005)$ apresentaram percepção mais positiva de qualidade de vida em diferentes domínios. Os domínios da qualidade de vida com mais atividades motoras associadas foram "saúde e atividade" e "convívio com outras pessoas". Envolvimento em diversas atividades motoras associou-se a melhor percepção da qualidade de vida, diferindo-se conforme frequência. Adolescentes que praticavam uma ou duas vezes por semana o futebol, basquete, lutas, natação, corrida, tênis/tênis de mesa e musculação, também como, os que praticavam, de três ou mais vezes na semana, a caminhada, voleibol, fazer exercício em academias de ginástica, corrida e andavam de bicicleta apresentaram percepção mais positiva da qualidade de vida que os não praticantes.
\end{abstract}

Palavras-chave: Qualidade de vida; Atividade motora; Comportamento do adolescente.

ABSTRACT

The aim of the study was to analyze the relationships between the involvement in different motor activities, according to the frequency of practice, and the perception of the quality of life of adolescents. A total of 773 adolescents from the state's schools of Paranagua (Paraná), aged 14 to 19, participated in the study. Using a self-administered questionnaire, was investigated sociodemographic information, motor activity (Physical Activity Questionnaire for Adolescents and perception of quality of life (Pediatric instrument Quality of Life Inventory ${ }^{T M}$ version 4.0. Adolescents was practiced soccer $(p<0.005)$, basketball $(p<0.005)$, fights $(p<0.005)$, bodybuilding $(p<0.001)$, tennis / table tennis $(p<0.005)$, swimming $(p<0.005)$, volleyball $(p<0.005)$, exercise in gymnasiums $(p<0.005)$ and cycling $(p<0.005)$ had a more positive perception of quality of life in different domains. The domains of quality of life with more associated motor activities were "health and activity" and "living with other people". Involvement in several motor activities was associated with a better perception of quality of life, differing according to frequency. Teenagers who practiced once or twice a week soccer, basketball, fights, swimming, running, tennis / table tennis and bodybuilding, as well as, practicing, three or more times a week, walking, volleyball, gymnastics, running and cycling had a more positive perception of quality of life than non-practitioners.

Keywords: Quality of life; Motor activity; Adolescent behavior.

\section{Introdução}

O termo qualidade de vida (QV) possui um conceito amplo $^{1}$ que inclui diversas condições que podem influenciar na percepção, nos sentimentos e comportamentos do indivíduo, não se limitando apenas às condições de saúde ${ }^{2}$. A QV não se restringe à satisfação com necessidades materiais, e sim, está relacionada com a inserção social, a liberdade e o bem-estar ${ }^{3}$. Com isso, mudanças no estilo de vida, como praticar atividades físicas regularmente, além de serem fundamentais para a promoção da saúde, podem contribuir na melhora da QV dos indivíduos.

No entanto, o estilo de vida não depende, exclusivamente, de uma escolha pessoal ${ }^{5}$, mas também de diversos outros fatores. Deste modo, por exemplo, o envolvimento com a atividade motora durante a adolescência é reduzido quando comparado com a prática durante a infância ${ }^{6}$, devido às mudanças comportamentais, matu- 
racionais e socioculturais durante a puberdade ${ }^{7}$, o que pode levar a agravos na saúde do adolescente. Para isso, soluções devem ser propostas para maior propagação das atividades motoras em adolescentes, tendo em vista que, em geral, a atividade física apresenta benefícios bem estabelecidos na literatura, incluindo reduções na pressão arterial e na adiposidade corporal ${ }^{8}$, e aumento da massa muscular ${ }^{9}$. Além disso, estudo de Azevedo et al. ${ }^{10}$ destaca a importância da atividade motora durante a adolescência por ser uma importante influência para que o indivíduo permaneça ativo durante a vida adulta.

Contudo, será que a percepção da QV, em seus domínios físico, emocional, social e ambiental, se mostra mais positiva em adolescentes que frequentemente são praticantes de diferentes modalidades, como correr, andar de bicicleta, jogar futebol e outras atividades motoras, comparados aos não praticantes? A literatura especializada é restrita sobre a QV dos adolescentes, especialmente considerando os tipos de atividades motoras e a frequência com que são realizadas. É possível observar que os poucos estudos encontrados na literatura pesquisada foram conduzidos em amostras com patologias específicas ${ }^{11,12}$ ou com análises de atividade física utilizando como referencial o tempo semanal em minutos e se restringindo a comparação de ativos e insuficientemente ativos ${ }^{13,14}$.

Diante disso, aponta-se como lacuna de conhecimento a escassez de análises que considerem as diferentes atividades motoras, e sua frequência de prática, desenvolvidas culturalmente pelos adolescentes e sua percepção de qualidade de vida, o que pode se reverter em incentivo para práticas de atividades motoras a serem oferecidas com maior frequência para esse público. Com isso, o objetivo do estudo foi analisar as relações entre o envolvimento em diferentes atividades motoras, de acordo com a frequência de prática, e a percepção de (QV) de adolescentes.

\section{Métodos}

Esta pesquisa, de cunho epidemiológico do tipo descritivo transversal, faz parte do macroprojeto "Sono, atividade física e desempenho escolar em adolescentes do município de Paranaguá (Paraná)” e foi desenvolvida de acordo com os princípios éticos, tendo aprovação junto ao Comitê de Ética em Pesquisas com Seres $\mathrm{Hu}-$ manos da Universidade do Estado de Santa Catarina, sob o parecer $n^{\circ}$ 1.671.544/2016.

A população de estudantes regularmente matriculados no ensino médio nas escolas estaduais no município de Paranaguá (Paraná), Brasil na época do estudo era de
6.108 adolescentes de 14 a 19 anos. Para o cálculo amostral foram adotados os critérios de Luiz \& Magnanini ${ }^{15}$, com nível de confiança de 1,96 (intervalo de confiança de 95\%), erro tolerável de cinco pontos percentuais, prevalência de $50 \%$ (desfecho não conhecido), e efeito de delineamento de 1,5 para amostra por conglomerado no segundo estágio da amostragem. Para minimizar as eventuais perdas relacionadas às possíveis recusas em participar do estudo, foram acrescentados 15\%. Com esses parâmetros, o tamanho amostral mínimo foi de 624 estudantes. A amostragem foi realizada em dois estágios, no primeiro estágio da amostragem, foram selecionadas, por conveniência, duas das escolas de maior porte e que recebiam alunos de todas as regiões do município. Sugeridas pelo representante legal e assistente técnico da chefia da Secretaria de Estado da Educação (SEED). No segundo estágio, todas as turmas do ensino médio das duas escolas participaram da coleta de dados, sendo que todos os alunos em sala de aula que assinaram o termo de Assentimento e que seus pais assinaram o Termo de Consentimento Livre e Esclarecido participaram da pesquisa. Por fim, devido à coleta de dados por conglomerado no segundo estágio da amostragem, a amostra final foi contabilizada em 773 alunos de 14 a 19 anos pertencentes às escolas estaduais no município.

A coleta de dados foi realizada por meio de um questionário autoaplicável, com adolescentes que assinaram o Termo de Assentimento e que seus responsáveis assinaram o Termo de Consentimento Livre e Esclarecido. As variáveis investigadas foram sexo (masculino, feminino), idade (14-19 anos), ano escolar $\left(1^{\circ}, 2^{\circ}\right.$ e $3^{\circ}$ ano do ensino médio), turno (matutino, vespertino, noturno) e classe socioeconômica (alta, média e baixa). Para este último utilizou-se o instrumento Critério de Classificação Econômica Brasil, de 2015, proposto pela Associação Brasileira de Empresas de Pesquisa ${ }^{16}$ o qual estima o poder aquisitivo das pessoas e famílias urbanas. A partir da soma dos pontos de cada questão, os indivíduos foram classificados em estratos econômicos (A, B1, B2, C1, C2, D/E). Em seguida, para fins de análise, foram agrupados em classe econômica alta (A, $\mathrm{B} 1)$, média (B2) e baixa (C1, C2, D/E).

As atividades motoras foram extraídas da primeira questão do Physical Activity Questionnaire for Children (PAQ-C) proposto por Crocker et al. ${ }^{17}$ e validado para ser utilizado com adolescentes, denominando-se Physical Activity Questionnaire for Adolescents (PAQ-A), por Kowalski et al. ${ }^{18}$ Traduzido e validado por Guedes e Guedes ${ }^{19}$ para português do Brasil. A questão 
refere-se à "atividade física no tempo livre" e questiona "você realizou alguma dessas atividades nos últimos 7 dias (última semana). Se a resposta for sim, quantas vezes foi realizada? (Marcar uma única resposta por atividade)". As atividades apresentadas foram pular-corda, andar de patins, brincar de pega-pega, andar de bicicleta, caminhar como exercício físico, correr, nadar, dançar, fazer exercício em academias de ginástica, fazer musculação, jogar basquetebol, jogar futebol/futsal, jogar voleibol, jogar handebol, jogar tênis de campo/tênis de mesa, lutar judô, karatê ou outras lutas. As respostas são do tipo Likert de 5 pontos, simbolizando quantas vezes na semana o adolescente realizou a atividade motora. Para fins de análise, as respostas foram agrupadas em não praticantes, praticantes de 1-2 vezes na semana e de 3 ou mais vezes na semana. Assim, "não praticantes" foram os que responderam "não". Já os praticantes que responderam 1-2 vezes na semana foram agrupados na categoria "1-2 vezes na semana" e os praticantes que responderam 3-4, 5-6 ou $\geq 7$ na semana foram agrupados em " $\geq 3$ vezes na semana".

A qualidade de vida relacionada à saúde foi investigada por meio do questionário Pediatric Quality of Life Inventory ${ }^{T M}$ versão 4.0 (PedsQL 4.0), desenvolvido e validado na língua inglesa por Varni et al. ${ }^{20}$. Posteriormente Klatchoian et al. ${ }^{21}$ traduziu e validou transculturalmente a versão brasileira seguindo a metodologia proposta pelos idealizadores da versão original em inglês. $\mathrm{O}$ instrumento possui 23 itens e abrange as dimensões Saúde e Atividades - oito itens, Sentimentos - cinco itens, Convívio com outras pessoas - cinco itens e Escolar - cinco itens. Cada item contém cinco opções de resposta numa escala Likert (nunca $=0$ a quase sempre $=4$ ). Os valores são operacionalizados posteriormente, os quais são transformados em escala linear inversa de 0 a 100, a pontuação maior representa melhor percepção da qualidade de vida. $\mathrm{O}$ questionário é pontuado no total e por dimensões, a partir da média das pontuações dos itens correspondentes.

As análises estatísticas foram realizadas no Software The Statistical Package for the Social Sciences (SPSS), versão 20.0. Foi verificado que os dados não apresentaram distribuição normal pelo teste de Kolmogorov-Smirnov, com isso, recorreram-se às análises não-paramétricas. Foram realizadas análises descritivas das variáveis contínuas representadas por média e desvio-padrão e das variáveis categóricas representadas por frequência relativa e absoluta. Para verificar as diferenças da percepção de QV e de cada domínio entre não praticantes, prati- cantes de 1-2 e $\geq 3$ vezes na semana de diferentes atividades motoras, recorreu-se ao teste Kruskal-Wallis com post-hoc Dunn. Todas as análises foram realizadas considerando um nível de probabilidade de confianças de 5\%.

\section{Resultados}

A amostra formada por 773 adolescentes apresentou média de idade de 16,2 anos (desvio padrão $=1,07$ ), em sua maioria estudaram no período diurno (91,8\%), apresentaram baixo nível econômico $(38,2 \%)$ e a maior porcentagem $(39,2 \%)$ estava alocada no segundo ano do ensino médio (Tabela 1 ).

Tabela 1 - Dados sociodemográficos de adolescentes de 14 a 19 anos, Paranaguá, Paraná, $2016(\mathrm{n}=773)$.

\begin{tabular}{lc}
\hline Variáveis & Todos \\
\hline Idade, anos & $16,2 \pm 1,07$ \\
Ano escolar, n (\%) & \\
$1^{\circ}$ Ensino médio & $206(26,6)$ \\
$2^{\circ}$ Ensino médio & $304(39,2)$ \\
$3^{\circ}$ Ensino médio & $263(34,0)$ \\
Turno de estudo, n (\%) & \\
$\quad$ Matutino & $414(53,6)$ \\
Vespertino & $296(38,3)$ \\
Noturno & $63(8,2)$ \\
Classe socioeconômica, n (\%) & \\
Baixa & $263(38,2)$ \\
Média & $254(36,9)$ \\
Alta & $171(24,9)$ \\
\hline
\end{tabular}

Valores descritos em média e \pm desvio-padrão para variáveis numéricas; para variáveis categóricas foi utilizado n: frequência absoluta; (\%): frequência relativa.

Ao verificar as percepções de QV dos adolescentes, dentre os domínios, o domínio Convívio com outras pessoas apresentou maior pontuação $(86,9)$ e em contrapartida, a menor pontuação foi observada no domínio Sentimentos $(58,8)$. A QV total, por sua vez, atingiu o terço superior da pontuação $(73,8)$. Tratando dos itens, a questão "Eu me preocupo com o que vai acontecer comigo" obteve menor pontuação $(44,6)$ e por outro lado, a questão "Para mim é difícil tomar banho de banheira ou de chuveiro sozinho/a" alcançou a maior pontuação $(98,9)$ (Tabela 2).

Quando questionados sobre as práticas de atividades motoras, no geral, mais da metade da amostra mencionou que andava de bicicleta $(54,0 \%)$, praticava a caminhada $(51,3 \%)$, e ainda com frequências elevadas, foram mencionados a corrida (46,4\%), o voleibol $(41,3 \%)$, o futebol $(36,6 \%)$ e a dança $(34,8 \%)$. Respectivamente as atividades andar de bicicleta e caminhada atingiram $27,7 \%$ e $24,1 \%$ de praticantes de três ou mais 
Tabela 2 - Valores médio e desvios-padrão das respectivas pontuações de percepção de qualidade de vida por meio da PedsQL 4.0 de adolescentes de 14 a 19 anos, Paranaguá, Paraná, 2016.

\begin{tabular}{|c|c|}
\hline Domínios da qualidade de vida & Todos \\
\hline $\begin{array}{l}\text { Domínio Saúde e atividades (SATV) } \\
\text { Para mim é difícil andar mais de um quarteirão } \\
\text { Para mim é difícil correr } \\
\text { Para mim é difícil praticar esporte ou fazer exercícios físicos } \\
\text { Para mim é difícil levantar coisas pesadas } \\
\text { Para mim é difícil tomar banho de banheira ou de chuveiro sozinho/a } \\
\text { Para mim é difícil ajudar nas tarefas domésticas } \\
\text { Eu sinto dor } \\
\text { Eu me sinto cansado/a e tenho pouca energia ou disposição } \\
\text { Total sobre saúde e atividades (SATV) }\end{array}$ & $\begin{array}{r}90,6 \pm 20,0 \\
80,6 \pm 27,5 \\
83,2 \pm 25,7 \\
73,4 \pm 29,4 \\
98,9 \pm 8,1 \\
83,2 \pm 25,3 \\
68,4 \pm 29,0 \\
66,3 \pm 29,8 \\
80,8 \pm 15,6\end{array}$ \\
\hline $\begin{array}{l}\text { Domínio Sentimentos (SENT) } \\
\text { Eu sinto medo } \\
\text { Eu me sinto triste } \\
\text { Eu sinto raiva } \\
\text { Eu durmo mal } \\
\text { Eu me preocupo com o que vai acontecer comigo } \\
\text { Total sobre sentimentos (SENT) }\end{array}$ & $\begin{array}{l}72,6 \pm 25,5 \\
63,3 \pm 28,2 \\
49,3 \pm 31,3 \\
64,2 \pm 30,2 \\
44,6 \pm 35,2 \\
58,8 \pm 21,1\end{array}$ \\
\hline $\begin{array}{l}\text { Domínio Convívio com outras pessoas (CONVI) } \\
\text { Eu tenho dificuldade para conviver com outros adolescentes } \\
\text { Os outros adolescentes não querem ser meus amigos } \\
\text { Os outros adolescentes implicam comigo } \\
\text { Não consigo fazer as coisas que as adolescentes da minha idade fazem } \\
\text { É difícil acompanhar as atividades com outros adolescentes } \\
\text { Total convívio com outras pessoas (CONVI) }\end{array}$ & $\begin{array}{l}83,1 \pm 25,1 \\
87,9 \pm 19,5 \\
85,4 \pm 22,1 \\
88,3 \pm 21,1 \\
89,4 \pm 19,3 \\
86,9 \pm 15,6\end{array}$ \\
\hline $\begin{array}{l}\text { Domínio Escola (ESCOLA) } \\
\text { É difícil prestar atenção na aula } \\
\text { Eu esqueço as coisas } \\
\text { Tenho dificuldades para acompanhar minha turma nas tarefas escolares } \\
\text { Eu falto à aula por não estar me sentindo bem } \\
\text { Eu falto à aula por ir ao médico ou ao hospital } \\
\text { Total sobre a escola (ESCOLA) }\end{array}$ & $\begin{array}{l}63,6 \pm 28,0 \\
51,2 \pm 29,2 \\
77,6 \pm 25,7 \\
74,9 \pm 26,9 \\
72,0 \pm 26,3 \\
68,0 \pm 17,6\end{array}$ \\
\hline Qualidade de vida total & $73,8 \pm 12,6$ \\
\hline
\end{tabular}

Valores expressos em média e \pm desvio-padrão.

vezes semanais. Ainda quanto à prática de $\geq 3$ vezes na semana, destaca-se também a corrida com 20,0\% e o futebol 17,9\% (maior frequência). Já considerando as atividades motoras de 1-2 vezes na semana (menor frequência), ressalta-se o voleibol com 28,6\%. Atividades como a natação, handebol, pular-corda, brincar de pega-pega e andar de patins não atingiram 10\% de praticantes (Tabela 3 ).

$\mathrm{Na}$ Tabela 4 foram expostas apenas as atividades motoras em que os praticantes (1-2 vezes na semana ou $\geq 3$ vezes na semana) apresentaram percepção mais positiva de QV em cada domínio (Saúde e Atividade, Sentimentos, Convívio com outras pessoas e Escola), comparando-se aos não praticantes da modalidade.

Assim, no domínio Saúde e Atividades, os envolvidos nas práticas de futebol, basquete, lutas, musculação, tênis/tênis de mesa $(p<0,001)$ e natação $(p=0,007)$ apresentaram percepção mais positiva de QV que os não praticantes. Ainda neste domínio, praticantes do voleibol $(p=0,007)$, que fazem exercício em academias de ginástica $(\mathrm{p}=0,002)$ e os que andavam de bicicleta $(\mathrm{p}<0,001)$ demonstraram maior percepção de $\mathrm{QV}$ quando envolvidos nestas atividades três ou mais vezes na semana, comparando-se tanto com não-praticantes, quanto aos praticantes de 1-2 vezes na semana, sendo que estes dois grupos não apresentaram diferença entre si ( $p>0,050)$. Em especial, praticantes da corrida de três ou mais vezes semanais apresentaram percepção mais positiva neste domínio comparando-se aos que corriam uma ou duas vezes na semana ( $<0,001)$, que por sua vez, indicaram percepção mais positiva que os não praticantes $(p<0,001)-($ Tabela 4$)$.

No domínio Sentimentos, apenas os praticantes de futebol $(\mathrm{p}<0,001)$ apresentaram percepção mais positiva de QV comparando-se aos não praticantes de futebol. Quando analisado o domínio Convívio com outras pessoas, foi verificada percepção mais positiva de QV em adolescentes que praticaram com frequência de uma ou duas vezes na semana a musculação ( $p$ $=0,006)$, basquete $(\mathrm{p}=0,012)$ e futebol $(\mathrm{p}<0,001)$. 
Tabela 3 - Frequência de não praticantes, praticantes de 1-2 e $\geq 3$ vezes na semana de atividade motora adolescentes de 14 a 19 anos, Paranaguá, Paraná, 2016 ( $\mathrm{n}=773)$.

\begin{tabular}{lccc}
\hline Atividade motora & Não pratica & n (\%) & $\begin{array}{c}1-2 \text { na semana } \\
\mathrm{n}(\%)\end{array}$ \\
\hline Andar de bicicleta & $352(46,0)$ & $201(26,3)$ & $212(27,7)$ \\
Caminhar & $374(48,7)$ & $209(27,2)$ & $185(24,1)$ \\
Correr & $414(53,7)$ & $203(26,3)$ & $154(20,0)$ \\
Voleibol & $451(58,7)$ & $220(28,6)$ & $97(12,6)$ \\
Futebol & $488(63,4)$ & $144(18,7)$ & $138(17,9)$ \\
Dançar & $502(65,2)$ & $167(21,7)$ & $101(13,1)$ \\
Tênis ou tênis de mesa & $628(81,7)$ & $82(10,7)$ & $59(7,7)$ \\
Musculação & $635(82,5)$ & $45(5,8)$ & $90(11,7)$ \\
Ginástica na academia & $660(85,9)$ & $40(5,2)$ & $68(8,9)$ \\
Basquete & $668(86,9)$ & $61(7,9)$ & $40(5,2)$ \\
Lutas & $685(89,2)$ & $41(5,3)$ & $42(5,5)$ \\
Natação & $703(91,2)$ & $50(6,5)$ & $18(2,3)$ \\
Handebol & $711(92,5)$ & $45(5,9)$ & $13(1,7)$ \\
Pular corda & $721(93,5)$ & $32(4,2)$ & $18(2,3)$ \\
Brincar de pega-pega & $725(94,2)$ & $38(4,9)$ & $7(0,9)$ \\
Andar de patins & $749(97,1)$ & $16(2,1)$ & $6(0,8)$ \\
\hline
\end{tabular}

Valores expressos em frequência e percentual, $\mathrm{n}(\%) .0$ = não praticante; $1-2=$ pratica $1-2$ na semana; $\geq 3$ = pratica três ou mais vezes na semana.

Ainda quanto a este domínio, os envolvidos no voleibol $(\mathrm{p}=0,002)$, os que andavam de bicicleta $(\mathrm{p}=0,002)$ e que corriam $(\mathrm{p}=0,004)$ necessitaram realizar estas práticas, com frequência mais elevada, três ou mais vezes na semana para que fosse evidenciada percepção mais positiva de QV comparando-se aos não praticantes das respectivas atividades motoras, pois não houve diferenças entre não praticantes e praticantes de uma a duas vezes por semana destas modalidades ( $p>0,050$ ). Por fim, a percepção mais positiva de qualidade de vida no domínio Escola foi evidenciada nos praticantes de voleibol $(p=0,007)$ e futebol $(p<0,001)-($ Tabela 4$)$.

$\mathrm{Na}$ análise da QV Total, também houve diferenças significativas entre os praticantes de voleibol $(\mathrm{p}=$ $0,001)$ e tênis/tênis de mesa $(\mathrm{p}=0,028)$ comparando-se aos não praticantes das respectivas atividades motoras. Além disso, foram observadas maiores percepções de QV Total em praticantes de três ou mais vezes na semana de musculação $(p=0,002)$, basquete $(\mathrm{p}=0,005)$ e que andavam de bicicleta $(\mathrm{p}<0,001)$ apenas comparando-se aos não praticantes das respectivas modalidades. Já os praticantes da corrida obtiveram maior percepção de QV Total quando praticavam três ou mais vezes, assim sendo superior a percepção dos não praticantes e praticantes de uma a duas vezes por semana. Contrariando as outras atividades motoras, participantes da dança apresentaram pior percepção de QV nos domínios sentimentos, saúde e atividade e qualidade de vida total comparando-se aos não praticantes (análises não apresentadas em quadro ou tabela).

\section{Discussão}

Este estudo teve como objetivo analisar as relações entre o envolvimento em diferentes atividades motoras, de acordo com a frequência de prática, e a percepção de (QV) de adolescentes. Para isso, foram estratificados em adolescentes não praticantes, praticantes de uma ou duas vezes na semana e os praticantes de três ou mais vezes semanais. A atividade motora com maior número de adeptos, com frequência de uma ou duas vezes por semana, foi o voleibol, que junto com o futebol são as atividades motoras culturalmente predominantes dentro da escola ${ }^{22}$.

Como o ambiente escolar possa ser, de alguma forma, um facilitador para a realização do voleibol e do futsal, pelo fornecimento, em maior quantidade, de materiais, espaços e treinamentos extraclasse que priorizam essas duas atividades motoras, estes fatos supostamente aumentariam o número de envolvidos. Além disso, tendo em vista que o domínio escolar está mais direcionado ao desempenho escolar, a revisão sistemática de Singh et. al. ${ }^{23}$ corrobora com os resultados do atual estudo, pois evidenciou que o envolvimento com atividades motoras, atividades esportivas na escola e a atividade física escolar podem predizer melhor desempenho escolar. Assim, consequentemente podendo melhorar a percepção de QV no domínio escolar desses adolescentes. 
Tabela 4 - Diferença de percepção de qualidade de vida, em seus domínios Saúde e atividades, Sentimentos, Convívio e Escola, de acordo com a frequência de prática das atividades motoras (não pratica ou pratica de 1-2 vezes e pratica $\geq 3$ vezes na semana).

\begin{tabular}{|c|c|c|c|c|}
\hline \multirow{2}{*}{ Atividades motoras* } & \multicolumn{4}{|c|}{ Domínios } \\
\hline & Saúde e atividades & Sentimentos & Convívio & Escola \\
\hline \multicolumn{5}{|l|}{ Corrida } \\
\hline Não pratica & $77,7(16,5)^{\mathrm{a}}$ & $58,1(21,2)$ & $85,8(16,0)$ & $67,3(17,2)^{a}$ \\
\hline Pratica $1-2$ vezes & $81,5(14,7)^{\mathrm{b}}$ & $58,0(20,9)$ & $86,5(16,2)$ & $67,6(18,0)^{2}$ \\
\hline Pratica $\geq 3$ vezes & $88,5(10,3)^{c}$ & $62,0(20,7)$ & $90,6(13,3)$ & $70,5(17,9)^{\mathrm{b}}$ \\
\hline $\mathrm{p}$-valor & $<0,001$ & 0,157 & 0,004 & 0,097 \\
\hline \multicolumn{5}{|l|}{ Futebol } \\
\hline Não pratica & $77,1(16,4)^{a}$ & $56,2(21,1)^{a}$ & $84,3(17,0)^{a}$ & $66\left(7(18,3)^{2}\right.$ \\
\hline Pratica $1-2$ vezes & $86,2(11,5)^{\mathrm{b}}$ & $61,4(19,9)^{b}$ & $90,4(12,2)^{b}$ & $70,0(16,0)^{\mathrm{b}}$ \\
\hline Pratica $\geq 3$ vezes & $88,8(10,5)^{\mathrm{b}}$ & $65,7(20,4)^{\mathrm{b}}$ & $92,2(11,1)^{b}$ & $70,3(16,1)^{\mathrm{b}}$ \\
\hline p-valor & $<0,001$ & $<0,001$ & $<0,001$ & 0,038 \\
\hline \multicolumn{5}{|l|}{ Voleibol } \\
\hline Não pratica & $79,4(16,5)^{a}$ & $58,3(22,0)$ & $85,0(16,8)^{a}$ & $66,1(18,2)^{a}$ \\
\hline Pratica $1-2$ vezes & $82,1(14,0)^{a, b}$ & $60,7(18,7)$ & $89,0(13,3)^{a, b}$ & $72,0(16,2)^{\mathrm{b}}$ \\
\hline Pratica $\geq 3$ vezes & $85,3(12,4)^{b}$ & $57,4(21,6)$ & $90,9(13,2)^{b}$ & $67,8(15,8)^{2}$ \\
\hline $\mathrm{p}$-valor & 0,007 & 0,399 & 0,002 & $<0,001$ \\
\hline \multicolumn{5}{|l|}{ Musculação } \\
\hline Não pratica & $90,4(15,9)^{a}$ & $58,4(21,2)$ & $86,1(16,0)^{a}$ & $67,7(17,6)$ \\
\hline Pratica $1-2$ vezes & $86,8(11,1)^{b}$ & $60,7(22,3)$ & $91,8(9,7)^{\mathrm{a}, \mathrm{b}}$ & $71,5(16,6)$ \\
\hline Pratica $\geq 3$ vezes & $88,0(11,1)^{b}$ & $61,4(19,5)$ & $90,4(14,9)^{b}$ & $68,2(18,1)$ \\
\hline $\mathrm{p}$-valor & $<0,001$ & 0,508 & 0,006 & 0,379 \\
\hline \multicolumn{5}{|l|}{ Tênis } \\
\hline Não pratica & $79,7(15,9)^{\mathrm{a}}$ & $58,2(21,2)$ & $86,5(16,1)$ & $67,4(17,5)$ \\
\hline Pratica 1-2 vezes & $85,9(12,3)^{\mathrm{b}}$ & $60,5(18,6)$ & $88,1(13,3)$ & $70,4(18,6)$ \\
\hline Pratica $\geq 3$ vezes & $85,8(13,5)^{\mathrm{b}}$ & $62,0(22,7)$ & $89,4(13,2)$ & $70,7(16,1)$ \\
\hline $\mathrm{p}$-valor & $<0,001$ & 0,218 & 0,493 & 0,150 \\
\hline \multicolumn{5}{|l|}{ Lutas } \\
\hline Não pratica & $80,0(15,9)^{\mathrm{a}}$ & $58,9(21,2)$ & $86,7(21,2)$ & $67,7(17,5)$ \\
\hline Pratica 1-2 vezes & $86,8(10,6)^{\mathrm{b}}$ & $56,8(19,4)$ & $86,5(16,8)$ & $70,0(18,3)$ \\
\hline Pratica $\geq 3$ vezes & $89,3(8,3)^{b}$ & $61,2(21,4)$ & $91,2(9,8)$ & $71,0(18,0)$ \\
\hline $\mathrm{p}$-valor & $<0,001$ & 0,544 & 0,415 & 0,388 \\
\hline \multicolumn{5}{|l|}{ Caminhar } \\
\hline Não pratica & $79,2(17,0)^{\mathrm{a}}$ & $59,5(22,3)$ & $86,4(15,7)$ & $67,3(17,5)$ \\
\hline Pratica 1-2 vezes & $80,8(14,1)^{a, b}$ & $58,5(20,1)$ & $87,2(15,7)$ & $67,4(17,8)$ \\
\hline Pratica $\geq 3$ vezes & $83,9(13,4)^{b}$ & $57,5(19,5)$ & $87,5(15,5)$ & $70,3(17,5)$ \\
\hline $\mathrm{p}$-valor & 0,018 & 0,563 & 0,717 & 0,073 \\
\hline \multicolumn{5}{|l|}{ Andar de bicicleta } \\
\hline Não pratica & $77,6(17,3)^{\mathrm{a}}$ & $58,1(21,8)$ & $85,0(16,5)^{\mathrm{a}}$ & $66,5(18,6)$ \\
\hline Pratica 1-2 vezes & $80,8(14,0)^{\mathrm{a}}$ & $58,8(20,5)$ & $87,9(14,4)^{\mathrm{a}, \mathrm{b}}$ & $68,0(16,7)$ \\
\hline Pratica $\geq 3$ vezes & $86,3(11,9)^{\mathrm{b}}$ & $60,8(20,1)$ & $89,4(14,9)^{b}$ & $70,4(16,5)$ \\
\hline $\mathrm{p}$-valor & $<0,001$ & 0,328 & 0,002 & 0,058 \\
\hline \multicolumn{5}{|l|}{ Basquete } \\
\hline Não pratica & $79,8(15,8)^{\mathrm{a}}$ & $58,4(21,7)$ & $86,2(16,0)^{a}$ & $67,7(17,4)$ \\
\hline Pratica 1-2 vezes & $88,8(9,7)^{\mathrm{b}}$ & $61,3(17,6)$ & $91,3(11,9)^{\mathrm{b}}$ & $68,7(18,1)$ \\
\hline Pratica $\geq 3$ vezes & $86,3(13,2)^{b}$ & $61,2(20,6)$ & $90,5(12,8)^{a, b}$ & $72,3(20,2)$ \\
\hline $\mathrm{p}$-valor & $<0,001$ & 0,343 & 0,012 & 0,205 \\
\hline \multicolumn{5}{|l|}{ Ginástica na academia } \\
\hline Não pratica & $80,1(15,8)^{a}$ & $59,0(21,3)$ & $86,4(16,0)$ & $68,0(17,4)$ \\
\hline Pratica 1-2 vezes & $83,6(14,0)^{\mathrm{a}, \mathrm{b}}$ & $58,1(19,4)$ & $903(10,9)$ & $69,9(15,6)$ \\
\hline Pratica $\geq 3$ vezes & $87,1(11,6)^{b}$ & $58,3(20,7)$ & $90,2(13,7)$ & $66,7(20,6)$ \\
\hline $\mathrm{p}$-valor & 0,002 & 0,792 & 0,086 & 0,695 \\
\hline \multicolumn{5}{|l|}{ Natação } \\
\hline Não pratica & $80,4(15,6)^{a}$ & $58,7(21,1)$ & $86,5(15,8)$ & $67,8(17,5)$ \\
\hline Pratica 1-2 vezes & $87,5(11,9)^{\mathrm{b}}$ & $60,4(21,7)$ & $91,8(11,0)$ & $71,1(17,9)$ \\
\hline Pratica $\geq 3$ vezes & $80,2(17,4)^{a, b}$ & $60,9(20,9)$ & $89,1(16,7)$ & $68,3(21,2)$ \\
\hline $\mathrm{p}$-valor & 0,007 & 0,909 & 0,076 & 0,425 \\
\hline
\end{tabular}

Letras distintas demonstram diferença estatisticamente significativa de acordo com o teste de Kruskall-Wallis. *as atividades motoras que não apresentavam quaisquer diferenças estatística de acordo com a percepção de qualidade de vida não foram incluídos na Tabela 4. 
A atividade motora menos relatada foi o patins, possivelmente por exigir uma série de condições para ser praticado, como piso propício (mais regular), equipamentos de segurança e o próprio patins que tem um custo mais elevado. Visto que a amostra estudada apresentou-se, em sua maioria, na classe socioeconômica baixa, não foi possível verificar a relação entre esta atividade motora e a percepção da qualidade de vida. Além disso, geralmente esta não é uma atividade motora incluída na Educação Física escolar, o que acrescenta as restrições para a prática dessa atividade e reduz a oportunidade de conhecimento desta atividade motora.

Considerando as dezesseis atividades motoras investigadas, os alunos envolvidos nas doze atividades mostraram percepção mais positiva de $\mathrm{QV}$ no domínio Saúde e Atividades comparando-se aos adolescentes não praticantes da respectiva modalidade. No que tange este fenômeno, parece estar bem estabelecido alguns benefícios da atividade motora que podem explicar essa relação, como o aumento da aptidão física ${ }^{9}$, redução dos fatores de risco cardiovascular ${ }^{24}$ e prevenção primária e secundária de doenças crônicas ${ }^{25}$.

Contudo, houve diferença entre as frequências de prática (1-2 vs. $\geq 3$ vezes na semana) e a percepção de $\mathrm{QV}$ neste domínio. Adolescentes que realizavam a corrida, futebol, tênis (mesa ou quadra), basquete, musculação, lutas e natação relataram percepção mais positiva apenas praticando uma ou duas vezes na semana. Ao passo que os que realizaram a caminhada, corrida, voleibol, fazer exercício em academias de ginástica e andar de bicicleta relataram maior percepção de QV neste domínio apenas quando exerciam a atividade motora regularmente.

Supõe-se que as atividades motoras de maior intensidade, e que exigem mais dos adolescentes praticantes melhorem a percepção de QV mesmo realizadas em baixa frequência semanal. Em contraponto, algumas atividades não necessitam ser realizadas com alta intensidade para que se garantam seus benefícios ${ }^{26}$, mas devem ser realizadas com maior frequência semanal para que os adolescentes possam perceber sua QV melhor. Um exemplo que sustenta essa hipótese foi o estudo de Moreira et al. ${ }^{27}$, comparando alunos de diferentes modalidades esportivas, sendo verificado em alunos de voleibol menor gasto calórico em comparação aos alunos do futebol devido ao maior tempo de atividade em intensidade vigorosa no futebol e em contrapartida, maior tempo em intensidade leve no voleibol, em ambos os sexos.

Além disso, nota-se que a corrida diferenças nas três categorias, corrida com frequência de $1-2$ e de $\geq 3$ vezes na semana apresentam percepção mais positiva de $\mathrm{QV}$ no domínio Saúde e Atividades, isso porque apenas a corrida mostrou-se estatisticamente diferente nas três situações. Tal situação pode ser justificada pelo fato de que os adolescentes praticantes em menor frequência (1-2 na semana) percebem mais positivamente a $Q V$ comparando-se aos não praticantes, porém corredores de maior frequência semanal (três ou mais vezes) percebem QV no domínio Saúde e Atividades ainda maior que corredores de 1-2 da semana e não praticantes.

Alguns adolescentes envolvidos nas atividades motoras coletivas voleibol, futebol e basquetebol e que praticavam a corrida, musculação e andavam de bicicleta apresentaram melhor percepção da $\mathrm{QV}$ no domínio Convívio com outras pessoas. Uma das explicações para isso, é que esses adolescentes podem ter menos restrições interpessoais, que segundo o modelo de restrições ao lazer de Crawford \& Godbey ${ }^{28}$ são uma das três categorias de restrições ao lazer que dizem respeito às decorrentes faltas de interações e relações com seus pares (por exemplo, a falta de companhia e falta de apoio/incentivo de amigos e/ou família). Com base neste princípio, pode-se afirmar que o suporte dos amigos pode predizer maior envolvimento na atividade física ${ }^{29}$ e nesse caso, beneficiam a QV no domínio Convívio com outras pessoas. Além disso, durante o repouso entre séries na musculação, as conversas antes e depois dos jogos coletivos e a organização da prática de corrida e ciclismo em grupo, estimulam a socialização com outras pessoas. Em apoio a isso, Gallahue et al..$^{30}$ apontam que as atividades motoras competitivas e cooperativas permitem aos jovens a oportunidade de desenvolvimento pessoal, também como, a interação e a integração social.

Algumas atividades como andar de patins, pega- pega, pular corda, jogar handebol e nadar não atingiram $10 \%$ de praticantes. O baixo percentual de participantes prejudica a capacidade de inferência estatística. Com isso, os resultados dessas atividades devem ser interpretados com cautela ao analisar os efeitos dessas práticas na qualidade de vida. Contudo, devido a amostra representativa, esses dados retratam a realidade nesta cidade, isso aponta que essas atividades motoras são pouco realizadas e que não fazem parte da realidade e do contexto cultural das aulas e vivências desses adolescentes. Recomenda-se pesquisas em outras realidades com maior percentual de praticantes dessas modalidades para verificar essa relação com a qualidade de vida. Além disso, sugere-se estudos de acompanhamento de adolescentes em meio às diferentes atividades motoras 
para que seja verificado com maior acuidade essa diferença da percepção da QV.

Como limitação do estudo, deve-se considerar que podem ter ocorrido respostas socialmente desejáveis, como a superestimação da atividade motora e isso pode subestimar o impacto benéfico da atividade motora na $\mathrm{QV}$ relacionada à saúde. Além disso, o tempo de prática não foi abordado, apenas que se considerassem muito ativos fisicamente em sua prática. Como ponto forte do estudo, a amostra é representativa dos adolescentes do ensino médio estadual da cidade de Paranaguá (Paraná). Além disso, destaca-se o uso do grande número de atividades motoras no estudo. Apesar da utilização do método de recordatório autorrelatado possibilitar o comprometimento da veracidade dos dados, este método é amplamente utilizado especialmente em grandes amostras, como a da atual pesquisa, já que é de baixo custo e relativamente mais rápido que os testes objetivos.

Foi identificado que o envolvimento em atividades motoras estava associado a melhor percepção de qualidade de vida, diferindo-se na frequência em que são praticadas. Assim, adolescentes que praticaram futebol, basquete, lutas, natação, corrida, tênis/tênis de mesa e musculação uma ou duas vezes por semana, também como, os que praticaram caminhada, voleibol, fazer exercício em academias de ginástica, corrida e andavam de bicicleta, três ou mais vezes na semana a apresentaram percepção mais positiva da qualidade de vida. Acerca desses resultados, deve ser incentivada maior prática de atividade motora, possibilitando que os adolescentes tenham mais vivências motoras, assim, melhorando a sua qualidade de vida.

\section{Declaração de conflito de interesses}

Os autores declaram não haver conflito de interesses.

\section{Contribuição dos autores}

Ferrari Junior GJ, participou da concepção inicial do estudo, coleta e análise dos dados, redação e revisão crítica do texto. Silva RC, participou da análise dos dados, redação e revisão crítica do texto. Soares BAC, participou da redação e revisão crítica do texto. Beltrame TS, Pelegrini A e Felden EPG participaram da concepção inicial do estudo, análise dos dados, redação e revisão crítica do texto.

\section{Referências}

1. Seidl EMF, Zannon CMLDC. Qualidade de vida e saúde: aspectos conceituais e metodológicos. Cad Saude Publica. 2004;20:580-8.

2. Bullinger $\mathrm{M}$, Anderson $\mathrm{R}$, Cella $\mathrm{D}$, Aaronson $\mathrm{N}$. Developing and evaluating cross-cultural instruments from minimum requirements to optimal models. Qual Life Res. 1993;2(6):451-9.
3. Minayo MCDS, Hartz ZMDA, Buss PM. Qualidade de vida e saúde: um debate necessário. Cienc Saude Colet. 2000;5(1):7-18.

4. Buss PM. Promoção da saúde e qualidade de vida. Cienc Saude Colet. 2000;5(1):163-77.

5. Pieron M. Estilo de vida, prática de atividades físicas e esportivas: qualidade de vida. Fit Perf J. 2004(1):10-7.

6. U. S. Departament of Health and Human Services. Physical activity and health: a report of the Surgeon General: diane Publishing; 1996.

7. Papalia DE, Feldman RD. Desenvolvimento humano: Artmed Editora; 2013.

8. Farpour-Lambert NJ, Aggoun Y, Marchand LM, Martin XE, Herrmann FR, Beghetti M. Physical activity reduces systemic blood pressure and improves early markers of atherosclerosis in pre-pubertal obese children. J Am Coll Cardiol. 2009;54(25):2396-406.

9. Rennie MJ. Body maintenance and repair: how food and exercise keep the musculoskeletal system in good shape. Exp Physiol. 2005;90(4):427-36.

10. Azevedo MR, Araújo CL, Silva MC, Hallal PC. Tracking of physical activity from adolescence to adulthood: a populationbased study. Rev Saude Publica. 2007;41(1):69-75.

11. Johansson H, Norlander K, Janson C, Malinovschi A, Nordang L, Emtner M. The relationship between exercise induced bronchial obstruction and health related quality of life in female and male adolescents from a general population. BMC Pulm Med. 2016;16(1):63.

12. Maher CA, Toohey M, Ferguson M. Physical activity predicts quality of life and happiness in children and adolescents with cerebral palsy. Disabil Rehabil. 2016;38(9):865-9.

13. Davies CA, Vandelanotte C, Duncan MJ, Van Uffelen JG. Associations of physical activity and screen-time on health related quality of life in adults. Prev Med. 2012;55(1):46-9.

14. Anokye NK, Trueman P, Green C, Pavey TG, Taylor RS. Physical activity and health related quality of life. BMC Public Health. 2012;12(1):624.

15. Luiz RR, Magnanini MM. A lógica da determinaçäo do tamanho da amostra em investigaçöes epidemiológicas. Cad Saúde Colet. 2000;8(2):9-28.

16. Associação Brasileira de Empresas de Pesquisa. Critério de classificação econômica Brasil, 2015. Disponível em: http:// www.abep.org/criterio-brasil. Acesso em 22 de Março de 2018.

17. Crocker P, Bailey DA, Faulkner RA, Kowalski KC, McGrath R. Measuring general levels of physical activity: preliminary evidence for the Physical Activity Questionnaire for Older Children. Med Sci Sports and Exerc. 1997;29(10):1344-9.

18. Kowalski KC, Crocker PR, Kowalski NP. Convergent validity of the physical activity questionnaire for adolescents. Pediatr Exerc Sci. 1997;9(4):342-52.

19. Guedes MS, Neto JLC. Avaliação da coordenação motora em crianças e adolescentes com deficiência auditiva: uma revisão sistemática de estudos brasileiros. Conexões. 2015;13(3):114-30.

20. Varni JW, Burwinkle TM, Seid M, Skarr D. The PedsQL ${ }^{\text {TM* }}$ 4.0 as a pediatric population health measure: feasibility, reliability, and validity. Ambul Pediatr. 2003;3(6):329-41.

21. Klatchoian DA, Len CA, Terreri MTRA, Silva M, Itamoto C, Ciconelli RM, et al. Qualidade de vida de crianças e adolescentes de São Paulo: confiabilidade e validade da versão brasileira do questionário genérico Pediatric Quality of Life InventoryTM versão 4.0. J Pediatr. 2008;84(4):308-15.

22. Burgos MS, Muller A, Burgos LT, Pohl HH, Reuter CP, Gaya AC, et al. Estilo de vida: lazer e atividades lúdicodesportivas de escolares de Santa Cruz do Sul. Rev Bras Educ Fís Esporte. 2009;23(1):77-86. 
23. Singh A, Uijtdewilligen L, Twisk JW, Van Mechelen W, Chinapaw MJ. Physical activity and performance at school: a systematic review of the literature including a methodological quality assessment. Arch Pediatr Adolesc Med. 2012;166(1):49-55.

24. Carnethon MR, Gidding SS, Nehgme R, Sidney S, Jacobs Jr DR, Liu K. Cardiorespiratory fitness in young adulthood and the development of cardiovascular disease risk factors. JAMA. 2003;290(23):3092-100.

25. Warburton DE, Nicol CW, Bredin SS. Health benefits of physical activity: the evidence. CMAJ. 2006;174(6):801-9.

26. Gonçalves A, Vilarta R. Qualidade de vida e atividade física: explorando teoria e prática. Baruerui, SP: Manole. 2004.

27. Moreira RB, Nina GL, Gaya AR, Nina PL, de Lemos AT, Gaya A. Níveis de atividade física em diferentes modalidades esportivas: um programa não convencional de Educação Física Escolar. Pensar Prát. 2016;19(4).
28. Crawford DW, Godbey G. Reconceptualizing barriers to family leisure. Leis Sci. 1987;9(2):119-27.

29. Van der Horst K, Paw M, TwiskJW, Van Mechelen W. A brief review on correlates of physical activity and sedentariness in youth. Med Sci Sports Exerc. 2007;39(8):1241.

30. Gallahue DL, Ozmun JC, Goodway JD. Compreendendo o desenvolvimento motor-: bebês, crianças, adolescentes e adultos: AMGH Editora; 2013.

Recebido: $12 / 12 / 2017$

Aprovado: 16/08/2018

\section{Como citar este artigo:}

Ferrari Junior GJ, Silva RC, Soares BAC, Beltrame TS, Pelegrini A, Felden EPG. Atividades motoras e qualidade de vida de adolescentes de Paranaguá, Paraná. Rev Bras Ativ Fís Saúde. 2018;23:e0018. DOI: 10.12820/rbafs.23e0018 